\title{
A Comparison of Waterproof Motor Housings for Student Robotics Teams
}

\author{
Charlie Diaz ${ }^{1}$ and Colin O'Connor"
}

1Jesuit High School, Carmichael, CA, USA

\#Advisor

\section{$\underline{\text { ABSTRACT }}$}

Professionals and students alike create high-performance Remotely Operated Vehicles (ROV)s to complete a multitude of tasks underwater. The student ROV competition created by Marine Advanced Technology Education (MATE) simulates the tasks faced by the modern professional underwater robotics industry. Students often design their ROVs with techniques used by the professional underwater robotics industry. Unlike professionals, students do not have many resources comparing manufacturable ROV components that fit within their design restrictions. Without information about components that they choose to use on their ROVs, students might miss an opportunity to implement a better alternative technology. Such is the case with older Shaft Sealed Housings (SSH) and less common Magnetically Coupled Housings (MCH). In this paper, essential aspects of both alternative designs for waterproof motor housings are tested to determine overall performance. The waterproofness of each housing is tested experimentally over long periods of time in an environment simulating the most extreme depths experienced at the MATE ROV Competition. Maximum static torque is measured on a torque sensor. Cost and manufacturability of each housing are recorded in tables. Ultimately, student robotics teams are left to determine which motor housing best fits their design requirements, based on the data discovered and presented in this paper.

\section{Introduction}

Underwater robotics is an expansive field. Many professionals and researchers in marine related industries have a vested interest in underwater operations. In order to operate underwater, professionals use remotely operated vehicles (ROVs) to accomplish tasks (Robison et al., 2017; Whitcomb, 2000; Mai, 2016). The construction and operation of ROVs are not limited to professionals. Students and amateurs alike often design, build and operate their own ROVs for recreation or for competition (Zande \& Brown, 2008; Rubin, 2013).

The Marine Advanced Technology Education (MATE) ROV Competition challenges student teams to create their own ROVs and complete various underwater tasks. The mission tasks that MATE creates are often inspired by the work that professional ROV operators do. MATE encourages student teams to approach tasks as if these student teams were professionals (2021 Explorer Manual, 2021). As a result, many student teams choose to replicate the methods and tools used by professionals to accomplish the professionally mimetic tasks that MATE has created.

Professional ROV operators choose tools based on how well the characteristics of the tool meets the requirements of the mission. Information about these tools are often made publicly available by manufacturers of tools. Research reports compile this information and present comparisons between different tools on the market ( $\mathrm{Sivc}^{`} \mathrm{ev}^{\mathrm{et}}$ al., 2018). Technical documentation and comparisons of important features allow ROV operators to make informed decisions regarding which tool most closely aligns with the criteria of their mission and other group-specific constraints such as cost.

In order for student robotics teams to emulate their professional counterparts and make educated tool selections in a similar fashion, student robotics teams must have access to 
documentation of student grade tools, such as underwater motor housings. The goal of this research is to create a comparison between two different variations on waterproof motor housings. The two types of housing under investigation are the shaft sealed housing and the magnetically coupled housing. Evaluation of the two housings will consist of observing the performance of each housing at its maximum static torque, determining the extent to which each housing is waterproof, as well as documenting the unit cost, total cost, and the methods of manufacturing used in the production of each housing. Ultimately student robotics teams will be able to use the information discovered about these housings to make informed decisions as to which housing is best suited for them.

\section{Literature Review}

Applications for remotely operated vehicles (ROVs) range from marine research to the servicing and monitoring of industrial equipment (Robison et al., 2017; Whitcomb, 2000; Mai, 2016, Salgado-Jimenez et al., 2010; Macreadie et al., 2018). Professional ROVs are created to perform tasks that are too dangerous for human divers (Whitcomb, 2000; Christ \& Wernli, 2013). ROVs are often used in the visual inspection of undersea cables (Mai, 2016), the collection of undersea organisms for research (Robison et al., 2017), the sample collection for underwater oil production systems, and the subsequent inspection of said underwater oil production systems (Salgado-Jimenez et al., 2010).

The Marine Advanced Technology Education (MATE) ROV Competition is an international student underwater robotics competition. The MATE ROV Competition's stated mission is to "Improve marine technical education and increase the number of highly skilled technical professionals who enter ocean-related occupations," (Zande \& Brown, 2008). MATE accomplishes this through designing their competition to reflect the challenges that professional ROV operators and designers face in their own line of work. One area of the competition where this is clearly evident is the set of mission tasks that student teams and their ROVs must complete underwater.

The MATE ROV Competition is heavily influenced by the professional underwater robotics industry. In the underwater portion of the competition, student teams must complete a variety of tasks with their custom built ROVs (2021 Explorer Manual, 2021). The tasks are reflective of the MATE ROV Competition's goals, in that they seek to simulate professional applications of ROVs found throughout marine industries and research (2021 Explorer Manual, 2021). As stated by the MATE ROV Competition's Executive Director, Jill Zande, “MATE's

ROV Competition presents middle school, high school, community college, and university students with the same types of challenges that scientists and engineers face when working in these environments," (Zande \& Brown, 2008). Due to the similarity of MATE ROV Competition tasks with tasks faced by professionals, many student teams have chosen to approach MATE ROV Competition tasks through implementing solutions similar to those found in professional marine industries (Cooney, 2006).

Professional ROV designers must create robust ROVs and tools that can fit a wide range of mission criteria. A popular tool design that can perform a wide range of tasks is the underwater manipulator (Christ \& Wernli, 2013). Underwater manipulators mimic the form and function of human arms, lending to their versatility (Christ \& Wernli, 2013). Underwater manipulators use joints, hydraulics, and electric motors to move and interact with their environment (Christ \& Wernli, 2013). These manipulators are often built to operate at depths of several thousand feet (Sivc` ev et al., 2018; Technology to extend your reach; Bowen et al., 2008; Christ \& Wernli, 2013). In order to withstand pressure at these depths, manipulators are made of high-quality materials such as titanium (Sivc` ev et al., 2018). The design, materials, and manufacturing processes that go into creating professional underwater manipulators are often reflected in the price of these manipulators, which can cost anywhere from tens of thousands to millions of dollars per unit (Sivc`ev et al., 2018).

Professional ROV operators have their own specific criteria for selecting ROVs and tools. These criteria are often determined by the tasks that ROV operators seek to accomplish as well as the budget available to ROV operators. In order to select from a wide range of available ROVs and ROV tools, comprehensive comparisons of ROV technologies and construction techniques (Capocci et al., 2017) as well as whole components such as underwater manipulators 
(Sivc`ev et al., 2018) allow ROV operators to make the most informed decisions about which devices they choose to use. Reviews such as Inspection-Class Remotely Operated Vehicles-A Review by Capocci et al. provide an overview of modern ROV technologies as well as a comparison of components used in the construction of ROVs (Capocci et al., 2017). Capocci et al. review variations on key components of an ROV as opposed to whole ROVs, allowing ROV operators to understand which specific technologies or materials, when integrated into a whole ROV, would be best suited to their application. Reviews of commercially available ROV tools, such as that by Sivc`ev et al., take a slightly different approach in their comparisons. Since underwater manipulators are complete units, Sivc `ev et al. compare the underwater manipulators holistically, taking into account many different aspects such as price, lift capacity, and depth rating of every underwater manipulator (Sivc` ${ }^{2}$ ev et al., 2018). Reviews that focus on off the shelf products such as underwater manipulators allow ROV operators to select entire tools that best fit the criteria set by ROV operators. Instances of students building analogs to professional grade ROV tools such as underwater manipulators or motor housings are documented in MATE ROV Competition mandated technical reports as well as individual student research reports (Cooney, 2006; Roberts, 2007). In reports such as MIT undergraduate Lauren Cooney's exploration of a low-cost underwater manipulator, a college student-grade underwater manipulator is developed and compared to one of its professional counterparts, the SCHILLING TITAN 4 (Cooney, 2006). Similarly, in a report by MIT undergraduate Megan Roberts a low-cost underwater manipulator is developed in response to the lack of inexpensive, commercially available waterproof servos (Roberts, 2007). In their reports, Cooney and Roberts both create student grade ROV tools that are both cheaper and more accessible than professional counterparts, however their use of a CNC milling machine in the manufacture of these housings may make these solutions inaccessible for student teams without access to automated mills.

In the MATE ROV Competition, shaft sealed housings (SSH) are the dominant method of sealing a motor in a waterproof enclosure. The underwater manipulators developed by Lauren Cooney and Megan Roberts are stereotypical examples of the SSH design philosophy (Cooney, 2006; Roberts, 2007). While these types of housings are common among student robotics teams, some aspects of their design may make them difficult to manufacture such as the common use of automated mills (Cooney, 2006; Roberts, 2007).

Student teams must balance the constraints imposed by the MATE ROV Competition such as underwater mission tasks as well as size and weight requirements with team-based constraints such as cost and available manufacturing methods. Similar to how professional ROV operators balance characteristics of tools such as underwater manipulators, student teams must find a balance between design constraints in order to create the most optimal solution to mission tasks. Effective balancing of such constraints requires teams to have a knowledge of the materials and components that they may choose to utilize in any given product. When building devices that incorporate existing technologies, such as tools that utilize powered rotational motion, teams must be familiar with the attributes of incorporated devices such as waterproof motor housings. A complete understanding of materials and components used in the creation of tools allow teams to combine them effectively and achieve specific design goals.

The magnetically coupled housing $(\mathrm{MCH})$ is a novel type of waterproof motor housing that is an alternative to the SSH. The MCH has not been employed as a design strategy in the MATE ROV competition, therefore little has been published about its manufacturing process or performance.

Comprehensive reviews of professional grade ROVs and underwater manipulators exist to allow professional ROV operators to choose ROV tools which best fit their mission criteria (Sivc $`$ ev et al., 2018). However, there has yet to be a similar review of student grade underwater motor housings, specifically a comparison between the SSH and $\mathrm{MCH}$. In order for student teams to emulate the design processes as well as the decision-making processes used by professionals in marine-related industries, student teams must have access to a review of student grade technologies.

The goal of this research is to fabricate, test, and then compare the operational characteristics of the SSH and MCH for reference by student robotics teams. By understanding the characteristics of each housing, student robotics teams will be able to make more informed decisions regarding which type of housing is best suited for their applications. 


\section{Methodology}

\section{Shaft Sealed Housing Description}

The Shaft Sealed Housing (SSH) (figure 1) is a popular variant of waterproof motor housing commonly used by MATE ROV Competition teams. The SSH uses a shaft directly attached to the output shaft of the motor to rotate any objects outside of the housing. One of the primary components of the SSH is a shaft seal, which is used to keep water from entering the housing through gaps between the shaft and the housing. Some student implementations of the SSH include a system in which oil floods the SSH, further preventing water from entering the housing (Roberts, 2007). However, the shaft seal itself still poses a potential point of failure for this system. As illustrated in figure 2, the shaft seal only contact seals around the shaft. If water were able to enter through gaps between the shaft and the shaft seal, the motor housing could flood with water.

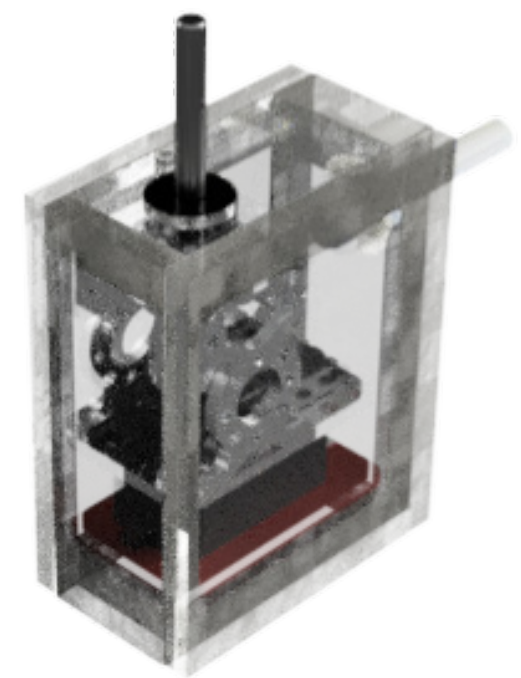

Figure 1. Render of the SSH. 


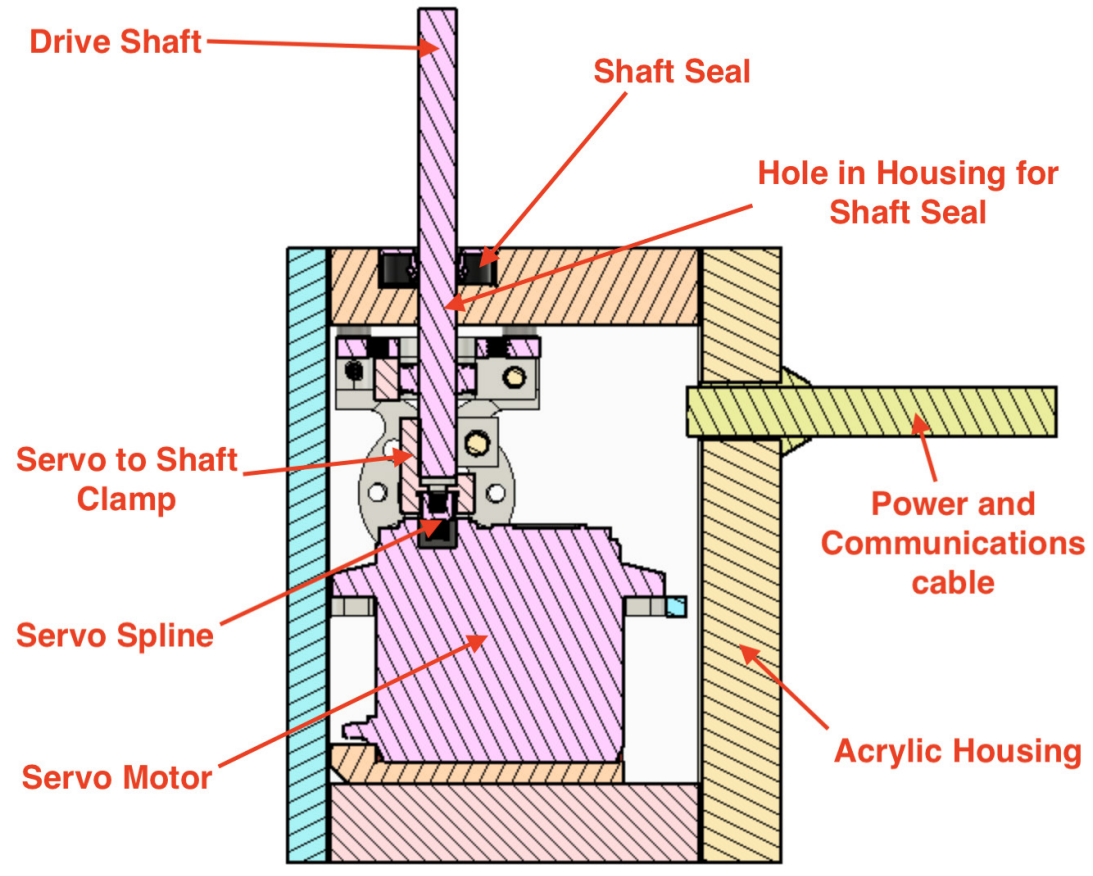

Figure 2. Cross section of the SSH.

\section{Magnetically Coupled Housing Description}

The Magnetically Coupled Housing (MCH) (figure 3) is a newer variant of waterproof motor housing and is therefore less commonly found on ROVs at the MATE ROV Competition. The central component of a MCH is the magnetic clutch through which the motor, housed inside of the housing, can propel an external shaft. The magnetic clutch consists of two primary components, the Internal Magnet Array (IMA) and the External Magnet Array (EMA) (figure 4). The IMA is attached to the output shaft or spline of the motor. The EMA is attached to a drive shaft. Through the positioning of magnets with alternating polarities along both the EMA and IMA, the magnetic clutch is able to utilize the attractive forces of opposite polarities and the repelling force of like polarities to propel an object external to the $\mathrm{MCH}$ without requiring the motor's drive shaft or spline to be directly attached to said object (figure 5). This gives the $\mathrm{MCH}$ an interesting attribute: there are no holes in a $\mathrm{MCH}$. As shown in figure 4 below, the $\mathrm{MCH}$ has no holes to allow a shaft to enter and exit the housing. This means that the MCH doesn't have the point of failure present in the $\mathrm{SSH}$ as an $\mathrm{MCH}$ needs no holes or seals through which to impel its torque. 


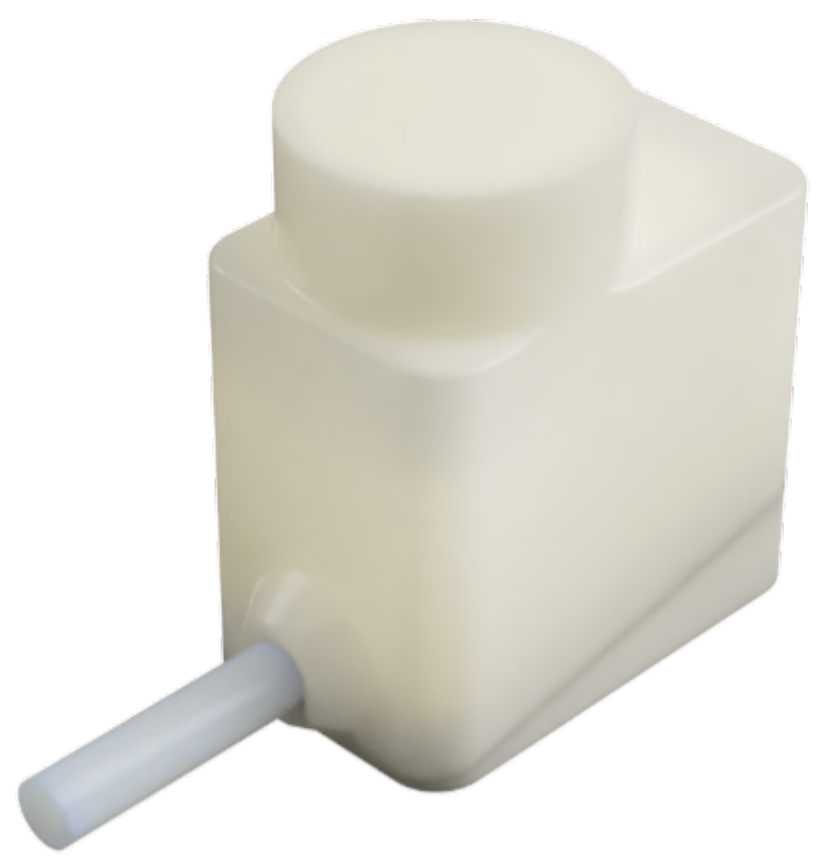

Figure 3. Render image of the $\mathrm{MCH}$.

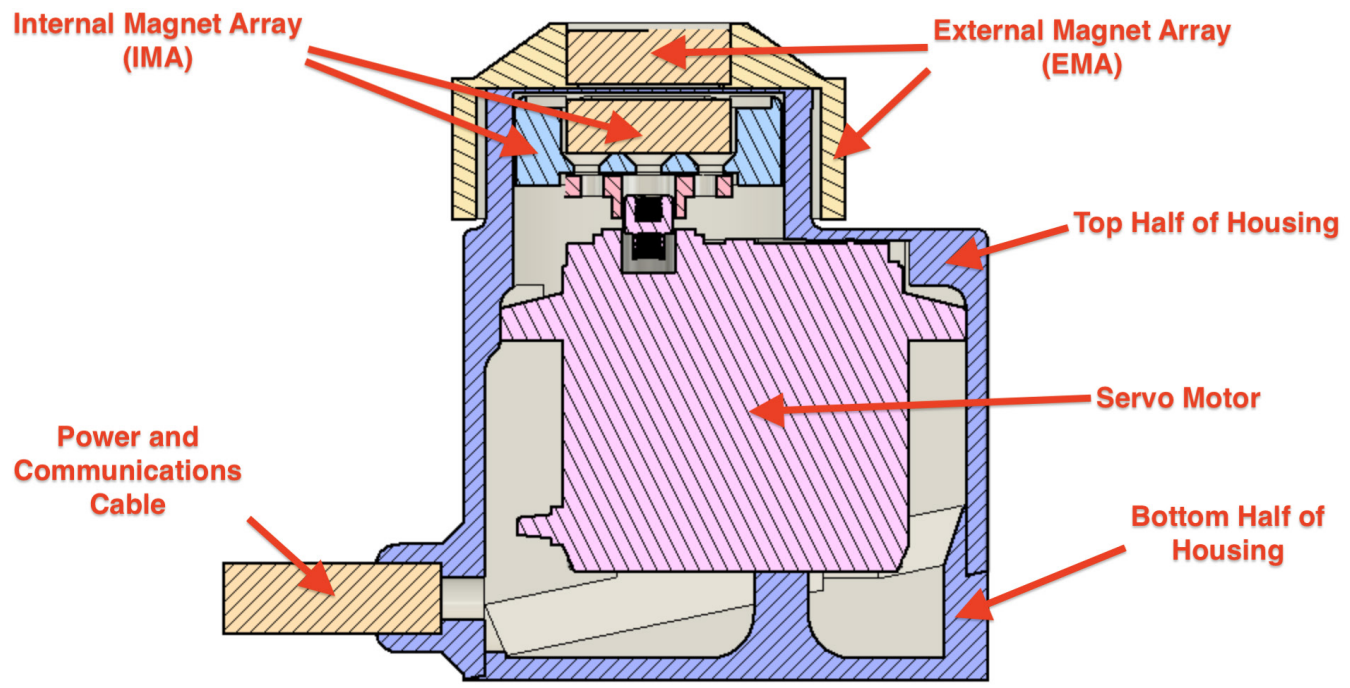

Figure 4. Cross section of the $\mathrm{MCH}$. 


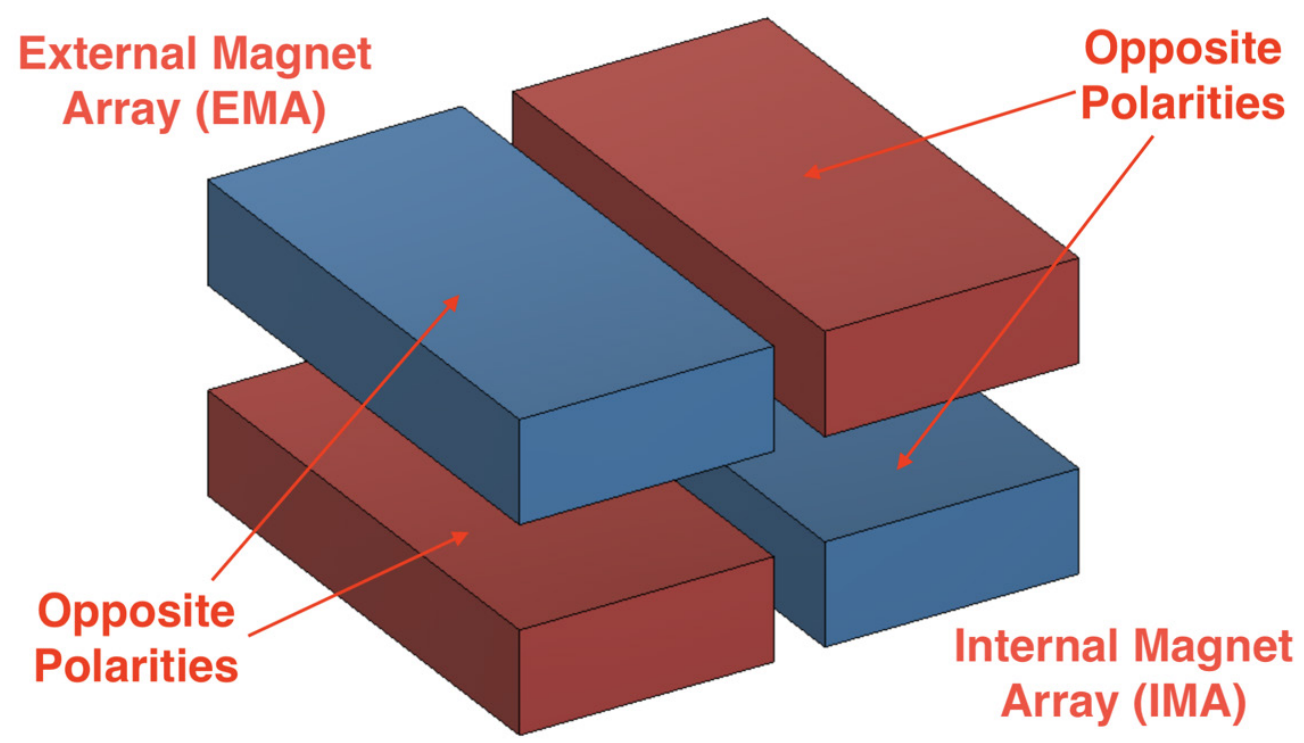

Figure 5. Illustration of the configuration of the magnets that make up the IMA and EMA.

\section{Waterproof Motor Housing Points of Comparison}

In order to present student robotics teams with relevant information about the SSH and MCH that can assist in the housing selection process, attributes of each housing must be recorded. The attributes chosen for comparison were: manufacturability, cost, maximum static torque, and waterproofness. These characteristics analyze some of the key features of underwater motor housings, and reflect common constraints faced by student robotics teams.

\section{Manufacturing Methods and Cost Calculation}

Student robotics teams generally do not have the same level of funding available to most professional ROV operators. Less funding for student teams results in student teams often not having access to tools such as automated mills. Therefore, many student teams may place an emphasis on how a product is manufactured. The manufacturing methods of both the SSH and MCH will be thoroughly documented. The type of tools used in each step of the manufacturing process will be documented, along with the time spent working with each tool. Included in the recordings for time spent working on the tool will be a short description of the work performed by the operator ${ }^{1}$.

Funding constraints affect not only the types of tools available to high school student robotics teams, but also the types of materials available for use in fabrication. Costs will be recorded in a Bill of Materials (BOM). It should be noted that for tests comparing torque and waterproofness, the same type of servo motor and sensors are used in both housings and will therefore be excluded from the BOM.

${ }^{1}$ If a tool listed was used in conjunction with other tools (for example, a drill bit used by a drill press), it will be listed as "NA" and reference the other tool for the time spent working approximation. Some aspects of the manufacturing and assembly process do not require direct interaction with the work, specifically the curing of epoxy or 3D printing. Time spent waiting for epoxy to cure and time spent waiting for an item to be 3D printed will both be included in the manufacturing method comparison. Time spent waiting for epoxy to cure will be identified by the phrase "Curing Time" and time spent waiting for a 3D print to complete will be identified by the phrase "Printing Time" each followed by an approximation of how much time each process took. 


\section{Maintaining Maximum Static Torque}

The primary use of waterproof housings is to physically rotate objects in their environment, which requires torque. When evaluating types of waterproof motor housings for use on their ROV, student robotics teams may have specific requirements for the maximum static torque output of their motor housing, and how consistent the maximum static torque applied by the housing is over long periods of time. Therefore, detailed measurements of maximum static torque for each motor housing will be recorded.

In order to measure maximum static torque for each housing and the effects that long periods of stress have on the maximum static torque; a torque sensor was created (figure 6). The torque sensor was constructed out of a postal scale ${ }^{2}$, a motor housing mount, a four-inch moment arm, a pushrod, an Arduino nano ${ }^{3}$, and an MPU6050 ${ }^{4}$

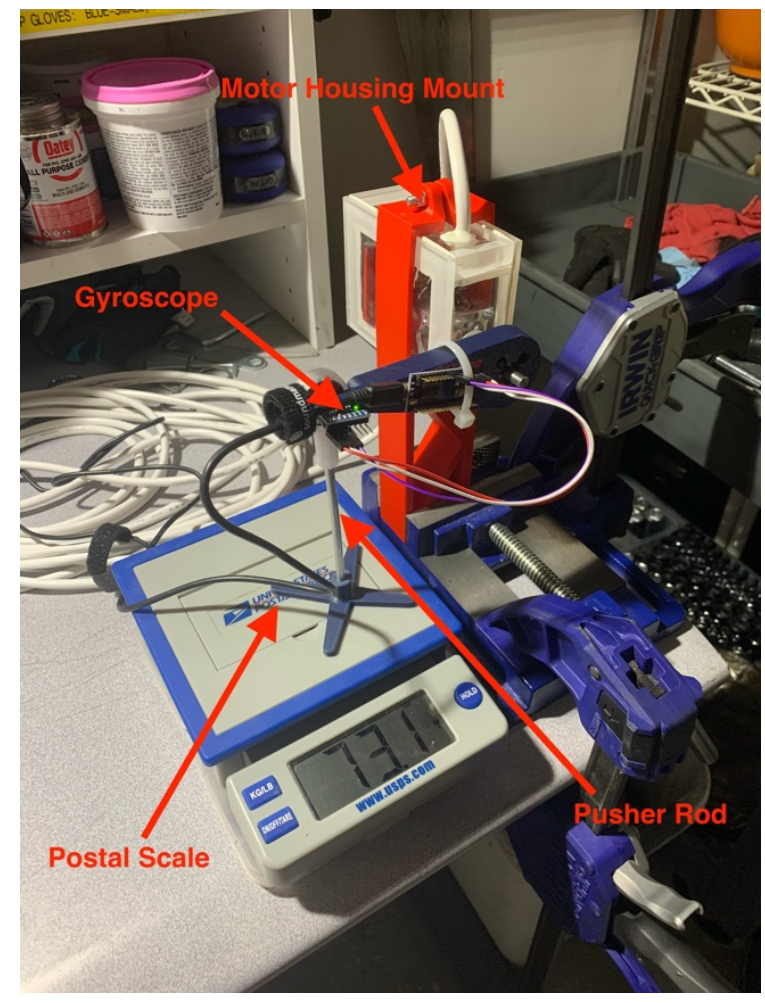

Figure 6. Pictured above is the static torque sensor.

To set up the torque sensor, the motor housing being tested was inserted into the motor mount. A clamp at the top of the motor housing mount was tightened in order to secure the motor housing to the mount. After securing the motor housing to the mount, the moment arm was fastened to the output shaft of the motor housing. Due to the disparate mechanisms by which the SSH and MCH convey rotational motion external to the housing, different styles of moment arm attachment were implemented.

${ }^{2}$ The postal scale used was manufactured by USPS with the intent that it be used to weigh mail up to 10 pounds in weight.

${ }^{3}$ The Arduino Nano is a small microcontroller. It was used to interface with the MPU6050 gyroscope in order to determine the angle of elevation of the moment arm.

${ }^{4}$ The MPU6050 is an Arduino-compatible accelerometer and gyroscope. It was used in conjunction with the Arduino Nano to determine the angle of elevation of the moment arm. 
The SSH's drive shaft is a steel shaft whose diameter is a quarter of an inch. Attachment of the moment arm to the SSH was accomplished by first securing a clamping hub to the SSH's drive shaft, followed by the fastening of the moment arm to the attachment points on the clamping hub.

Since the MCH doesn't have a physically coupled drive shaft, attachment of the moment arm to the $\mathrm{MCH}$ was entirely different from the method used for the SSH. To allow for attachment of the moment arm to the MCH, an EMA was built into the moment arm. The augmentation of the moment arm only affected the way in which the moment arm was attached to the $\mathrm{MCH}$ and did not affect the overall length of the moment arm, which if changed would cause the maximum torque recorded by the $\mathrm{MCH}$ to be inaccurate. To attach the modified moment arm to the $\mathrm{MCH}$, the EMA portion of the moment arm was brought close to the location of the IMA within the MCH. The EMA was manually rotated until the magnetic clutch engaged, fastening the moment arm to the MCH.

After the moment arm was attached to the motor housing, the Arduino nano was turned on, and began receiving data from the MPU6050. It was attached to the moment arm and measured the angle of inclination of the moment arm, relative to the horizon.

To test the SSH, the moment arm was rotated until the pad of the push rod was a few millimeters from the surface of the postal scale. The moment arm was then lowered onto the postal scale, and the servo motor inside the housing was programmed to rotate against the static postal scale for the duration of each trial.

The MCH's maximum static torque was determined before performing the long duration static torque tests. Finding the MCH's maximum static torque consisted of lowering the pad of the push rod to the surface of the postal scale and programming the servo motor to continue to rotate until the magnetic clutch disengaged. This method was repeated several times and averaged in order to increase measurement precision. After determining the maximum static torque, long duration testing began on the $\mathrm{MCH}$. This consisted of programming the servo motor to rotate until the experimentally determined maximum static torque was reached. The servo motor was then programmed to hold this position for the duration of each trial.

Four data points were collected during each trial: force experienced by the postal scale at the beginning of each trial, moment arm angle at the beginning of each trial, the force experienced by the postal scale at the end of each trial, and the moment arm angle at the end of each trial. The data collected at the beginning and end of each trial were combined in a formula (equation 1) to calculate the static torque of the motor during the beginning and end of each trial.

Equation 1: Used to determine static torque of motors.

$\tau=F r \sin \Theta$

In the above equation $\tau, F, r$, and $\Theta$, respectively represent, torque, the force measured by the postal scale, the radius of the moment arm (a constant four inches), and the angle formed between the moment arm and the pusher rod. The length of these trials was dictated by the maximum length of a MATE ROV Competition mission, which is fifteen minutes long (2021 Explorer Manual, 2021). The fifteen-minute trials were repeated twentyfive times in order to determine the effects that long term exposure to highly mechanically stressful environments have on each of these housings and their motors.

\section{Waterproofness}

Waterproof motor housings are built with the expressed purpose of creating a dry environment in which electric motors can operate. In order to determine to what extent each housing was waterproof, each housing was submerged in eighteen feet of water, where the pressure on the housings would be approximately 7.78 psi. Eighteen feet was chosen as the testing depth due to the guidelines MATE specified as the maximum operating depth for their 2021 competition (2021 Explorer Manual, 2021). In order to achieve a depth of eighteen feet, a four-inch inner diameter PVC pipe with 
a length of eighteen feet was positioned perpendicular to the ground. Once in position, the PVC pipe was filled with water, creating an environment at the bottom of the pipe similar to the maximum depth experienced at a MATE ROV Competition.

Once a housing was completely submerged, the motor inside of it was programmed to rotate continuously for periods of fifteen minutes. Continuous rotation was chosen to simulate the motor housing performing an operation during a mission. At the beginning and end of each trial, the internal relative humidity and temperature of each housing was recorded using an Adafruit HTS221 ${ }^{5}$. Relative humidity was measured in order to determine if water had entered the enclosure. Relative humidity, expressed as a percentage, is the ratio of the partial pressure water vapor relative to the equilibrium vapor pressure of water in a given environment (Wilhelm, 1976).

Equation 2: Relative humidity, expressed as the quotient of partial pressure of water vapor and the equilibrium vapor pressure of water

$$
\% \text { relative humidity }=\frac{\text { partial pressure of water vapor }}{\text { equilibrium vapor pressure of water }}
$$

If water were to somehow enter either of the waterproof housings, over time some of the water would evaporate, increasing the partial pressure water vapor, which would increase the relative humidity. Therefore, if an increase in relative humidity in one of the housings were recorded, it would indicate that some aspect of the housing had failed, letting water into the housing. In the case of the $\mathrm{SSH}$, due to its clear construction, if a significant increase in relative humidity were observed, it would be removed from the water and visually inspected. Due to the fact that the MCH had no clear components, a similar visual inspection would not be possible. The fifteen-minute trials were conducted twenty-five times in order to determine the effects that long-term exposure to wet, high-pressure environments had on each of the housings.

\section{Results}

\section{Manufacturing Methods}

Table 1. The manufacturing methods of the SSH.

\begin{tabular}{|c|c|c|c|}
\hline $\begin{array}{l}\text { Motor } \\
\text { Housing }\end{array}$ & Tools Used & Brief Description of Tool Use & $\begin{array}{l}\text { Approximation of } \\
\text { Time Spent with } \\
\text { Tool }\end{array}$ \\
\hline \multirow[t]{4}{*}{ SSH } & Band Saw & $\begin{array}{l}\text { The band saw was used to cut the clear acrylic panels that form the hous- } \\
\text { ing. }\end{array}$ & 1 hour \\
\hline & $\begin{array}{l}100 \quad \text { Grit } \\
\text { Sandpaper }\end{array}$ & $\begin{array}{l}100 \text { Grit Sandpaper was used to finish the rough edges created by the } \\
\text { band saw AND to create texture along areas on the panel where epoxy } \\
\text { would be applied. }\end{array}$ & 30 minutes \\
\hline & $\begin{array}{l}600 \quad \text { Grit } \\
\text { Sandpaper }\end{array}$ & $\begin{array}{l}600 \text { grit sandpaper was used exclusively to further finish the rough edges } \\
\text { left by the band saw. }\end{array}$ & 30 minutes \\
\hline & Drill Press & $\begin{array}{l}\text { The drill press was used to drill holes for the power and communications } \\
\text { cable, the hole for the shaft, as well as the indentation for the shaft seal } \\
\text { in the panels of the housing. }\end{array}$ & 30 minutes \\
\hline
\end{tabular}

${ }^{5}$ The Adafruit HTS221 is an Arduino compatible temperature and humidity sensor breakout board. 


\begin{tabular}{|c|c|c|c|}
\hline & 1/4" Drill & $\begin{array}{l}\text { The } 1 / 4 " \text { drill was used to drill the hole for the shaft as well as the power } \\
\text { and communications cable. }\end{array}$ & $\begin{array}{l}\text { NA - refer to Drill } \\
\text { Press }\end{array}$ \\
\hline & $\begin{array}{l}3 / 4^{\prime \prime} \quad \text { Forst- } \\
\text { ner Bit }\end{array}$ & $\begin{array}{l}\text { The } 3 / 4 \text { " forstner bit was used with the drill press to form the indentation } \\
\text { for the shaft seal. }\end{array}$ & $\begin{array}{l}\text { NA - refer to Drill } \\
\text { Press }\end{array}$ \\
\hline & 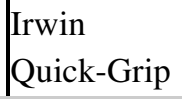 & Irwin Quick-Grips held the housing together while the epoxy set. & $\begin{array}{l}\text { NA - refer to Marine } \\
\text { Epoxy }\end{array}$ \\
\hline & Prusa & $\begin{array}{l}\text { The Prusa i3 MK3 3D printer was used to print the lower servo and sensor } \\
\text { support. }\end{array}$ & $\begin{array}{l}\text { Printing Time: } 52 \\
\text { minutes }\end{array}$ \\
\hline & F Clamps & Used to secure acrylic panels to the drill press during drilling. & $\begin{array}{l}\text { NA - refer to Drill } \\
\text { Press }\end{array}$ \\
\hline & $\begin{array}{l}\text { Marine } \\
\text { Epoxy }\end{array}$ & $\begin{array}{l}\text { Used to secure the acrylic housing panels together and seal the power and } \\
\text { communications wire. }\end{array}$ & $\begin{array}{l}\text { Curing Time: } 24 \\
\text { hours }\end{array}$ \\
\hline $\begin{array}{l}\text { TOTAL } \\
\text { TIME }\end{array}$ & & & $\begin{array}{l}\sim 27 \text { hours and } 30 \\
\text { minutes }\end{array}$ \\
\hline
\end{tabular}

Table 2. The manufacturing methods of the $\mathrm{MCH}$.

\begin{tabular}{|c|c|c|c|}
\hline $\begin{array}{l}\text { Motor } \\
\text { Housing }\end{array}$ & Tools Used & Brief Description of Tool Use & $\begin{array}{l}\text { Approximation of Time } \\
\text { Spent with Tool }\end{array}$ \\
\hline \multirow[t]{6}{*}{$\mathrm{MCH}$} & $\begin{array}{l}\text { Prusa } \\
\text { MK3 }\end{array}$ & $\begin{array}{l}3 \text { The Prusa i3 MK3 3D printer was used to print the body of the } \\
\text { MCH. }\end{array}$ & 8 hours and 36 minutes \\
\hline & $\begin{array}{l}\text { Irwin Quick } \\
\text { Grip }\end{array}$ & $\begin{array}{l}\text { Irwin Quick-Grips were used to hold the housing suspended } \\
\text { above the ground while the appliance epoxy and marine epoxy } \\
\text { dried. }\end{array}$ & $\begin{array}{l}\text { NA - refer to Marine Epoxy } \\
\text { and Appliance Epoxy }\end{array}$ \\
\hline & $\begin{array}{ll}100 & \text { Gri } \\
\text { Sandpaper }\end{array}$ & $\begin{array}{l}\text { it } 100 \text { grit sandpaper was used to finish the } \mathrm{MCH} \text { housing compo- } \\
\text { nents after printing. }\end{array}$ & 45 minutes \\
\hline & $\begin{array}{l}600 \quad \text { Grip } \\
\text { Sandpaper }\end{array}$ & $\begin{array}{l}\text { p } 600 \text { grit sandpaper was used to finish the MCH housing compo- } \\
\text { nents after printing. }\end{array}$ & 45 minutes \\
\hline & $\begin{array}{l}\text { Marine } \\
\text { Epoxy }\end{array}$ & $\begin{array}{l}\text { Used to secure the two halves of the } \mathrm{MCH} \text { together, seal the } \\
\text { power and communications wire, and coat the entire housing. }\end{array}$ & 24 hours \\
\hline & $\begin{array}{l}\text { Appliance } \\
\text { Epoxy }\end{array}$ & $\begin{array}{l}\text { Used as a final layer of sealant over the Marine Epoxy to ensure } \\
\text { waterproofness }\end{array}$ & 24 hours \\
\hline $\begin{array}{l}\text { TOTAL } \\
\text { TIME }\end{array}$ & & & $\sim 58$ hours \\
\hline
\end{tabular}

Bill

Table 3. The BOM of the SSH.

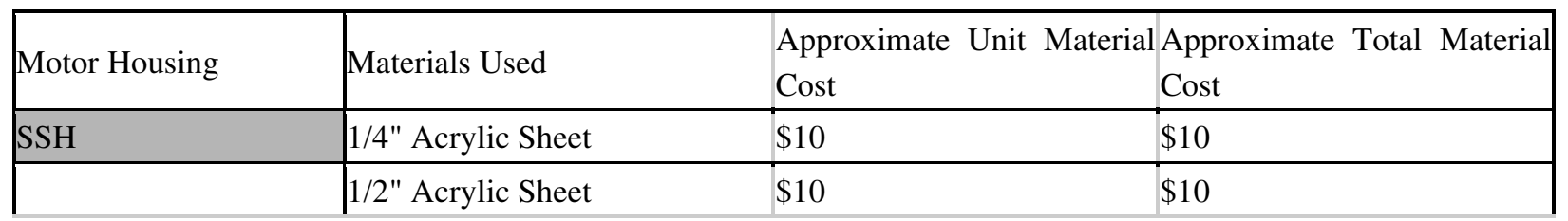




\begin{tabular}{|c|c|c|c|}
\hline & Marine Epoxy & $\sim 99.00$ & $\$ 18.99$ \\
\hline & Servo to Shaft Clamping Hub & $\$ 6.99$ & $\$ 6.99$ \\
\hline & $\begin{array}{l}3 " \text { long } 1 / 4 " \text { Stainless Steel } \\
\text { Shaft }\end{array}$ & $\$ 1.39$ & $\$ 1.39$ \\
\hline & $\mid \begin{array}{lll}\text { Sprint-Loaded } & \text { Rotary } & \text { Shaft } \\
\text { Seal }\end{array}$ & $\$ 16.96$ & $\$ 16.96$ \\
\hline & Standard Servo Plate & $\$ 4.99$ & $\$ 4.99$ \\
\hline & Side Tapped Pattern Mount B & $\$ 9.98$ & $\$ 9.98$ \\
\hline & Side Tapped Pattern Mount C & $\$ 5.99$ & $\$ 5.99$ \\
\hline & $\mid \begin{array}{l}1.75 \mathrm{~mm} \text { PETG 3D Printer Fila- } \\
\text { ment }\end{array}$ & $\$ 0.24$ & $\$ 21.99$ \\
\hline & 6-32 Screws & $\$ 1.53$ & $\$ 2.39$ \\
\hline \begin{tabular}{|ll} 
SSH & UNIT/TOTAL \\
COST &
\end{tabular} & & $\$ 77.07$ & $\$ 109.67$ \\
\hline
\end{tabular}

Table 4. The BOM of the MCH.

\begin{tabular}{|l|l|l|l|}
\hline Motor Housing & Materials Used & \multicolumn{1}{|l|}{$\begin{array}{l}\text { Approximate Unit Material } \\
\text { Cost }\end{array}$} & \multicolumn{1}{|l|}{$\begin{array}{l}\text { Approximate Total Material } \\
\text { Cost }\end{array}$} \\
\hline MCH & $\begin{array}{l}1.75 \text { mm PETG 3D Printer Fila- } \\
\text { ment }\end{array}$ & $\$ 1.51$ & $\$ 21.99$ \\
\hline & Appliance Epoxy & $\sim \$ 4.48$ & $\$ 4.48$ \\
\hline & Marine Epoxy & $\$ 18.99$ & $\$ 18.99$ \\
\hline & Short Strand Fiberglass Filler & $\sim \$ 1.00$ & $\$ 16.35$ \\
\hline & Aluminum Servo Horn & $\$ 1.20$ & $\$ 11.99$ \\
\hline $\begin{array}{l}\text { MCH } \\
\text { COST }\end{array}$ & M3 Screws & $\$ 0.18$ & $\$ 10.98$ \\
\hline
\end{tabular}

\section{Results of Maximum Static Torque Trials}

The results of the SSH and MCH torque trials are graphed below (Figure 7), where the x-axis is the trial number, and the y-axis is torque in ounce-inches (oz-in). The measured static torque at the beginning and end of each trial for the $\mathrm{MCH}$ are very similar, and on the graph appear to be the exact same line but are in fact different lines. 


\section{Initial Torque and Final Torque Comparison (Oz in)}

Initial Torque SSH

Final Torque SSH
Initial Torque $\mathrm{MCH}$

Final Torque $\mathrm{MCH}$

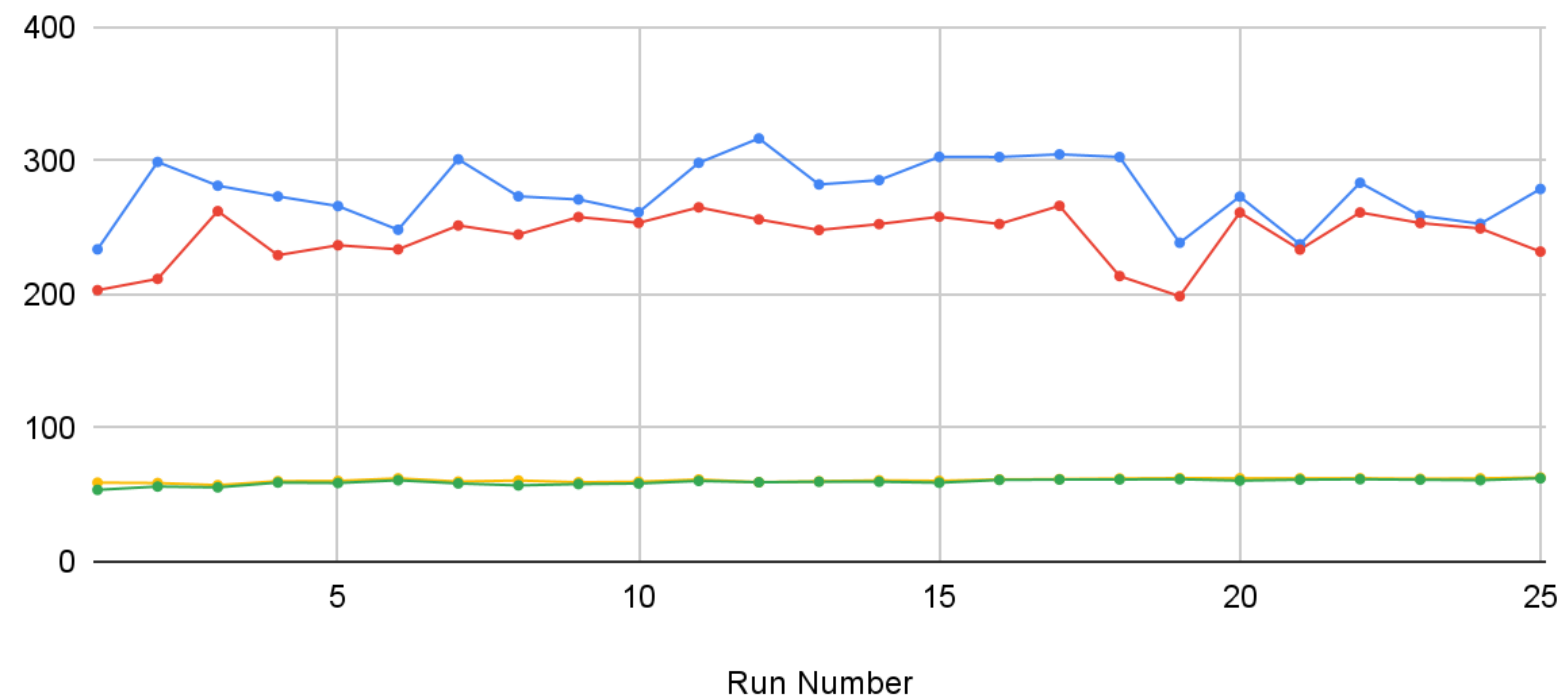

Figure 7. Experimentally determined torque comparison of SSH and $\mathrm{MCH}$.

\section{Results of Water Trials}

The results of the SSH and MCH underwater trials are graphed below (Figure 8), where the $\mathrm{x}$-axis is the trial number, and the $y$-axis is the percent relative humidity measured inside of each housing. The measured relative humidity at the beginning and end of each trial for the $\mathrm{MCH}$ are very similar, and on the graph appear to be the exact same line but are in fact different lines.

At the end of the SSH's second trial, the relative humidity measured inside of the housing increased from an initial $60 \%$ to $65 \%$. This increase was deemed large enough to warrant a visual inspection, and so the SSH was removed from the water and visually inspected. Water was seen to have begun forming along the gap between the shaft and the housing, meaning that water had entered the housing through the shaft seal (Figure 9). The increase in relative humidity and subsequent visual inspection provided sufficient evidence showing that the SSH had failed only thirty minutes into testing. When the SSH was placed back into the water sometime later, the initial measured relative humidity was $91 \%$. At this point it was already documented that the housing had failed, and relative humidity no longer provided vital information as to the waterproofness of the SSH. After water was determined to be entering the housing from the shaft seal, the water trials continued, and visual inspection occurred after every trial. Notable observations include the oxidation of several steel components, and the formation of condensation on the acrylic panels of the SSH. 


\section{Initial Relative Humidity and Final Relative Humidity Comparison $(\% \mathrm{RH})$}

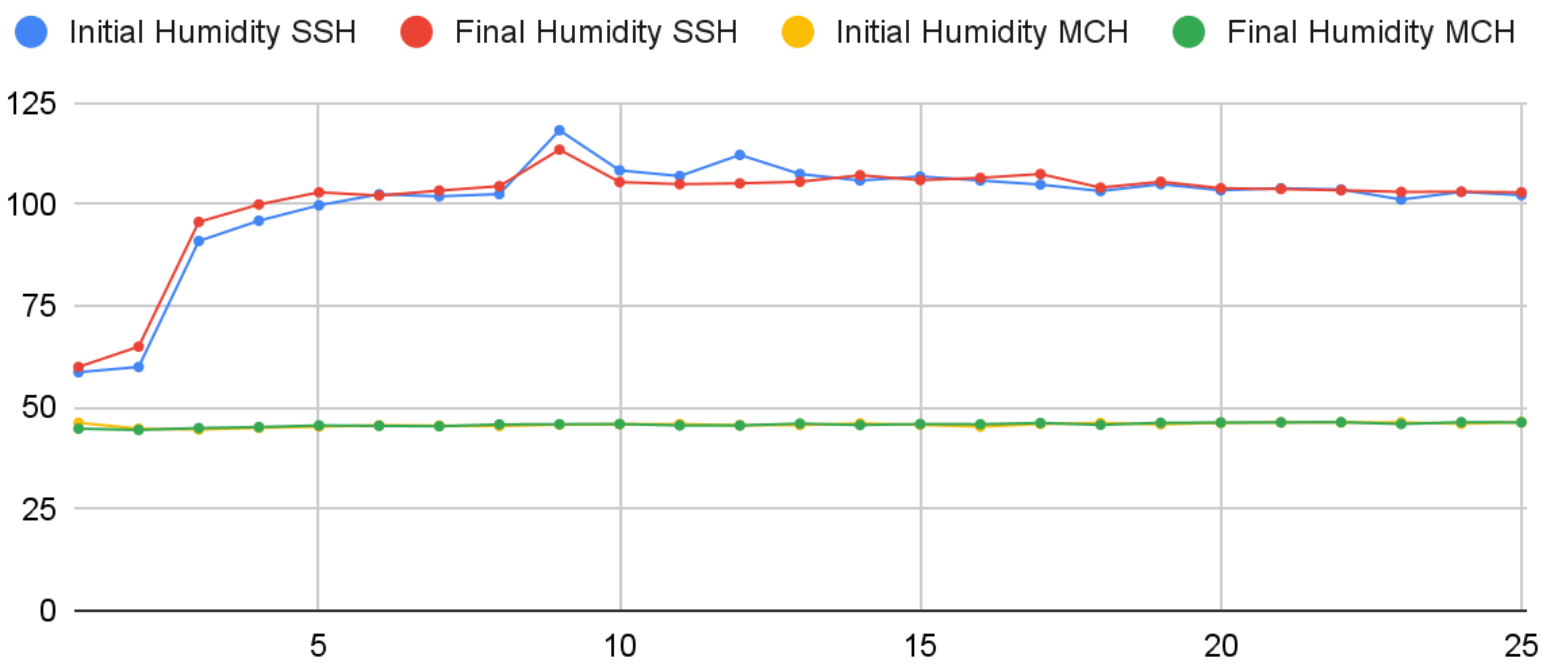

Run Number

Figure 8. Experimentally determined relative humidity comparison of SSH and $\mathrm{MCH}$.

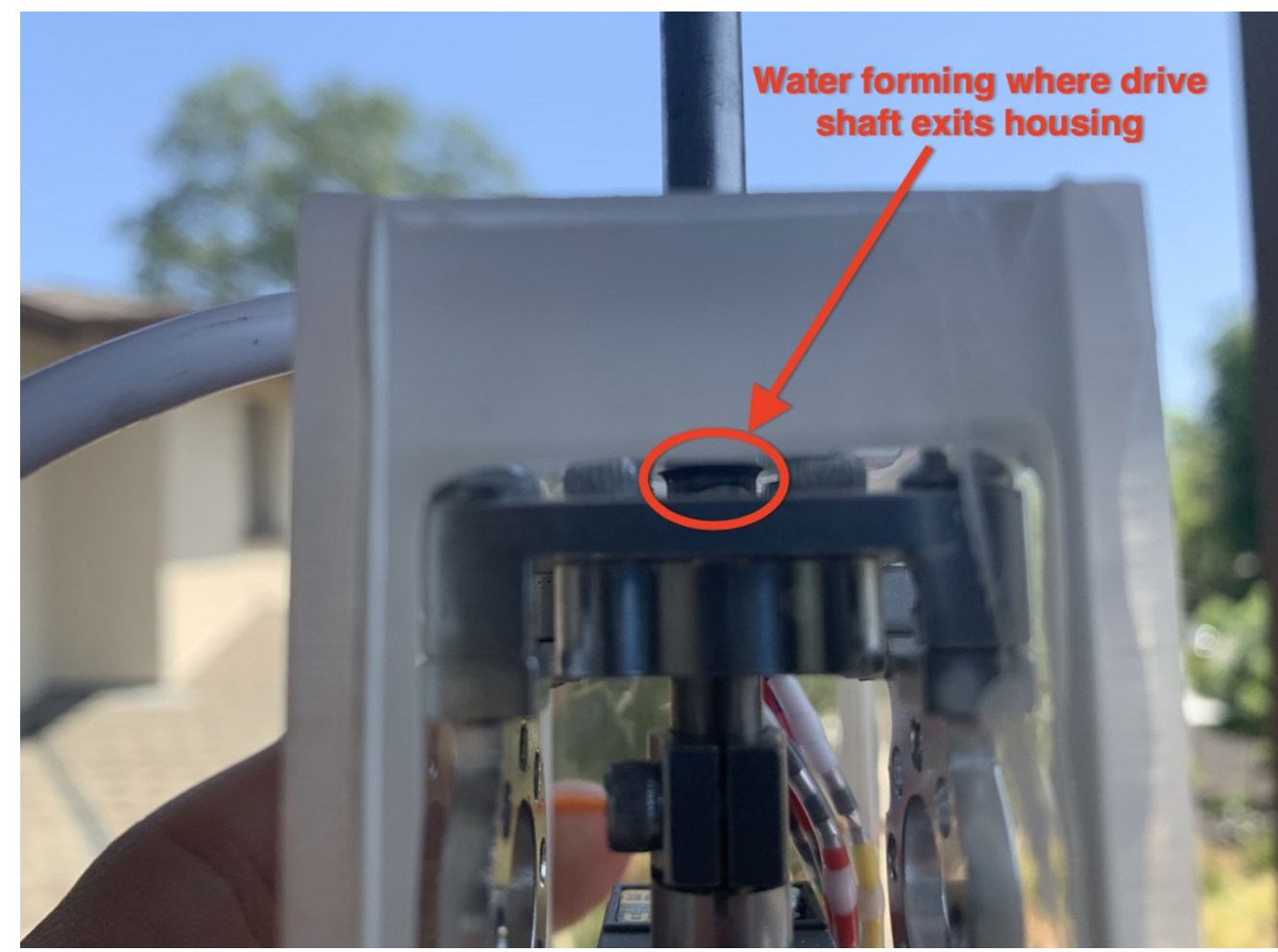


Figure 9. Image of the SSH after thirty minutes of testing. Water is clearly forming around the hole through which the drive shaft exits the housing, which at the time was the only collection of water visible in the housing.

\section{Discussion}

The documentation of the manufacturing process as well as the results from the torque and water tests provide useful information pertaining to some of the most important qualities of student produced underwater motor housings. The experimentally determined characteristics of the $\mathrm{MCH}$ and $\mathrm{SSH}$ illustrate how each housing lends themselves to different types of applications and design constraints.

The manufacturing methods of the SSH and $\mathrm{MCH}$, while sharing some common points such as the use of epoxy and sandpaper, are generally very different from each other. The majority of the SSH was built using manual manufacturing methods, employing a bandsaw and a drill press, both of which were operated by a student. In contrast, the body of the $\mathrm{MCH}$ was manufactured using an automated 3D printer set to print at a layer height of $0.05 \mathrm{~mm}$, a level of accuracy that is typically difficult for students to reach using manual tools. The difference in accuracy between manual and automated manufacturing methods may manifest itself in the quality of the end product. Student teams who decide to use an SSH on their ROV may have to go to considerable lengths to design a reliable, replicable manual method of manufacture in order to achieve an acceptable level of product consistency. Since the SSH is manufactured manually and therefore with a lower level of precision relative to the $\mathrm{MCH}$, the SSH may be subject to errors that might not be present in the MCH. Failure to manufacture an SSH with a high level of precision may result in water entering the housing through the shaft seal. This exact issue was observed at the end of the second water trial of the SSH, where water was clearly seen entering the SSH through the shaft seal (Figure 9). An alternative solution to the problem of imprecise SSH production, and all of the performance issues that it entails, would be to manufacture the SSH using automated manufacturing methods, such as 3D printing. By 3D printing the SSH housing in a similar way to how the MCH was produced, a high level of SSH quality may be achievable.

Manufacturing methods influence not only the performance of the housings, but the price of the housings as well. As shown at the bottom of Table 3 and Table 4, the unit price of the MCH was nearly three times lower than the unit price of the SSH. The disparity between the unit prices of each housing are largely attributable to the methods by which each housing was manufactured. The SSH was manufactured using methods that required more expensive materials relative to the $\mathrm{MCH}$ which was able to be manufactured with a 3D printer at an incredibly low price. The SSH required specialty parts such as servo blocks and shaft seals which caused the cost of the SSH to skyrocket. In comparison, the $\mathrm{MCH}$ was able to circumvent the exorbitant cost of specialty hardware by integrating many specialty components such as servo blocks into the overall design of the MCH's 3D printed parts.

If student teams decided to approach building a SSH using a 3D printer, they may be able to not only improve the precision of their manufacturing process, but also reduce the costs of production.

The results of the torque tests demonstrated that the $\mathrm{SSH}$ has a significantly higher maximum static torque than the $\mathrm{MCH}$. In some instances, the SSH had up to five times the maximum static torque of the $\mathrm{MCH}$. One key observation is that the SSH's maximum static torque, while constantly higher than the maximum static torque of the $\mathrm{MCH}$, was anything but consistent. As shown in figure 7, the maximum static torque varied greatly across different trials, and even from the start of one trial to the end of the trial. Variation of initial and final static torque for any given trial could range from a drop off of nearly ninety oz-in to only about $3 \mathrm{oz}$-in. This unreliability in performance at maximum static torque may be unacceptable to student teams looking for reliability and replicability in the performance of their tools. In addition, due to the direct-drive nature of the SSH, any load placed on the drive shaft of the SSH will be directly transmitted to the motor housed in the SSH. While direct drive has the demonstrated benefit of large amounts of torque, it may also come at the expense of damaging the motor housed inside of the SSH.

In contrast, the $\mathrm{MCH}$ had a lower, but a more precise maximum static torque. As demonstrated throughout the MCH's torque trials, and illustrated in Figure 7, the MCH's maximum static torque was close to sixty oz-in. While the MCH's maximum static torque is significantly lower than that of the SSH, the MCH's maximum static torque is 
also significantly more consistent than that of the SSH. Across all the MCH's torque trials, the average difference in maximum static torque from the beginning to end of each trial was only 1.359 oz-in, with a maximum variation between the beginning and end of trials of only $5.4 \mathrm{oz}-\mathrm{in}$. The precision of the MCH's maximum static torque can be advantageous in many ways. Teams looking for repeatability in tools will find consistent performance from the MCH. Since the $\mathrm{MCH}$ is not directly driven and has a maximum static torque limit of about sixty oz-in, the motor housed in the MCH will experience significantly less wear than one housed in an SSH.

Based on the findings of this research, student teams looking for a motor housing that can deliver high amounts of torque, but which may have a lower product longevity and high unit prices may choose to use an SSH, while student teams looking for a housing that is low cost, highly waterproof, but which delivers less torque may decide to implement a MCH. Ultimately, it is up to the student teams to use the information discovered and presented in this research to make informed decisions about which type of motor housing is best for them.

\section{Limitations}

In professional documentation of underwater manipulators, many different aspects of an underwater manipulator are rigorously tested and recorded. Due to constraints on my budget, I was unable to test as many aspects of each housing as I would have liked to. For example, initially I wanted to use a rotating torque sensor to determine the torque output of the housings at different speeds. Rotating torque sensors were deemed too expensive, and so I decided to create my own torque sensor which unfortunately was only capable of measuring static torque. In addition to limiting what torque I was able to test, the torque sensor I created was likely less accurate than a professionally manufactured rotational torque sensor so some of my values may have been slightly inaccurate.

Limitation on budget also affected my ability to test the waterproofness of each housing. Professional companies often test their product in deep ocean pressure simulators to determine the maximum operating depth of their product. Since I could neither afford a pressure simulator nor the cost of sending my housings to a facility dedicated to simulating deep ocean pressure, I could not test the housings to determine their maximum operating depth. This limitation on my ability to test each housing's maximum operational depth resulted in the pivot to test the housings at a constant depth, the maximum depth specified by MATE for their competition.

One of the largest limitations on this research was the number of housings that could be tested, which itself is an extension of my limited budget. Since I could only afford to create one prototype of each housing, I could not examine whether features of a housing, like the SSH's tendency to leak, were common among multiple different housings and thus a product of the design of the housing itself. It is therefore entirely possible that the less than favorable results of the SSH's water test are not inherent to the SSH itself or the components used but are instead solely attributable to mistakes made in the manufacturing of the SSH prototype tested in this research. Through the refining of techniques used in the manufacturing of the SSH, it may be possible to produce SSHs which don't leak through the shaft seal, that said it should also be noted that the $\mathrm{MCH}$ has no shaft seal to perfect, once again lending to the MCH's excellent performance during the water tests.

The prototype housings tested cannot be said to be completely representative of every version of SSH or $\mathrm{MCH}$ produced by student robotics teams, meaning that the results of this research, while possibly indicative of trends common to each housing type, may also be misleading.

\section{Future Research}

Student robotics teams, just like their professional counterparts, require detailed analyses of available tools in order to make the most informed tool selections as possible. One of the largest limitations on this research was which aspects of the $\mathrm{MCH}$ and SSH could be analyzed. In order to provide a more complete comparison of underwater motor housings for use by student robotics teams, future research should test and compare different aspects of the MCH and SSH. 
The other primary limitation, the fact that only one prototype of each housing was examined, could be remediated by other student robotics teams replicating methods used in this research with their own versions of the MCH and SSH. The publication of results from many different robotics teams would ultimately lead to a more robust understanding of the features inherent to each housing, and a more complete comparison of these two variations on waterproof housings.

\section{Acknowledgments}

I would like to thank my teacher Mr. Colin O'Connor, who gave me the opportunity to perform research at my high school and whose guidance throughout my two years in the AP Capstone program led me to a deeper understanding of the research process itself. I also would like to thank my mentors Mr. Jay Isaacs, Mrs. Cheryl Kiyama, and Mr. Steve Kiyama, for teaching me to engineer balanced solutions to complex real-world problems. Finally, I would like to thank my family, whose support and encouragement inspires me to pursue my interests.

\section{References}

Bowen, A. D., Yoerger, D. R., Taylor, C., McCabe, R., Howland, J., Gomez-Ibanez, D., ... \& Jakuba, M. V. (2008, September). The Nereus hybrid underwater robotic vehicle for global ocean science operations to $11,000 \mathrm{~m}$ depth. In OCEANS 2008 (pp. 1-10). IEEE.

Capocci, R., Dooly, G., Omerdić, E., Coleman, J., Newe, T., \& Toal, D. (2017). Inspection-class remotely operated vehicles-A review. Journal of Marine Science and Engineering, 5(1), 13.

Cooney, L. A. (2006). Development of a low-cost underwater manipulator (Doctoral dissertation, Massachusetts Institute of Technology).

Christ, R. D., \& Wernli Sr, R. L. (2013). The ROV manual: a user guide for remotely operated vehicles. Butterworth-Heinemann.

Macreadie, P. I., McLean, D. L., Thomson, P. G., Partridge, J. C., Jones, D. O., Gates, A. R., ... \& Fowler, A. M. (2018). Eyes in the sea: unlocking the mysteries of the ocean using industrial, remotely operated vehicles (ROVs). Science of the Total Environment, 634, 1077-1091.

Mai, C., Pedersen, S., Hansen, L., Jepsen, K. L., \& Yang, Z. (2016, December). Subsea infrastructure inspection: A review study. In 2016 IEEE International Conference on Underwater System Technology: Theory and Applications (USYS) (pp. 71-76). IEEE.

Roberts, M. J. (2007). Design of small, low-cost, underwater fin manipulator (Doctoral dissertation, Massachusetts Institute of Technology).

Robison, B. H., Reisenbichler, K. R., \& Sherlock, R. E. (2017). The coevolution of midwater research and ROV technology at MBARI. Oceanography, 30(4), 26-37.

Rubin, S. (2013, September). Mini-ROVs, going where no ROV has gone before. In 2013 OCEANS-San Diego (pp. 1-4). IEEE. 
Salgado-Jimenez, T., Gonzalez-Lopez, J. L., Martinez-Soto, L. F., Olguin-Lopez, E., Resendiz-Gonzalez, P. A., \& Bandala-Sanchez, M. (2010, May). Deep water ROV design for the Mexican oil industry. In OCEANS'10 IEEE SYDNEY (pp. 1-6). IEEE.

Sivc`ev, S., Coleman, J., Omerdić, E., Dooly, G., \& Toal, D. (2018). Underwater manipulators: A review. Ocean Engineering, 163, 431-450.

Technology to extend your reach. (n.d.). Retrieved May 21, 2021, from http://krafttelerobotics.com/products/predator.htm

Whitcomb, L. L. (2000, April). Underwater robotics: Out of the research laboratory and into the field. In Proceedings 2000 ICRA. Millennium Conference. IEEE International Conference on Robotics and Automation. Symposia Proceedings (Cat. No. 00CH37065) (Vol. 1, pp. 709-716). IEEE.

Wilhelm, L. R. (1976). Numerical calculation of psychrometric properties in SI units. Transactions of the ASAE, 19(2), 318-0321.

Zande, J., \& Brown, C. (2008). ROV Competition Helps Students Develop Technical Skills and Build Marine Technical Workforce [Education]. IEEE Robotics \& Automation Magazine, 15(1), 18-20.

2021 Explorer Manual. (2021, May 10). Retrieved May 13, 2021, from https://files.materovcompetition.org/2021/2021_EXPLORER_Manual_10May2021.pdf 